\title{
Retraction Note: Analytical investigations and fuzzy logic-based modeling of the impact resistance of aluminum-epoxy laminated composites
}

\author{
NAZARI Ali* \& DIDEHVAR Neda \\ Department of Materials Science and Engineering, Saveh Branch, Islamic Azad University, Saveh, Iran
}

The Journal Editorial Office has retracted this article [1] because it significantly overlaps with a number of articles including those that were under consideration at the same time [2,3] and previously published articles [4]. Additionally, the article shows evidence of peer review manipulation.

The editor was not able to obtain a current email address for Author Neda Didehvar. Author Ali Nazari did not respond to any correspondence from the editor or publisher about this retraction.

1 Nazari A, Didehvar N. Analytical investigations and fuzzy logic-based modeling of the impact resistance of aluminum-epoxy laminated composites. Sci China Tech Sci, 2011, 54: 2785-2794, https://doi.org/ 10.1007/s11431-011-4531-9

2 Nazari A, Didehvar N. Analytical modeling impact resistance of aluminum-epoxy laminated composites. Compos Part B-Eng, 2011, 42: 1912-1919, https://doi.org/10.1016/j.compositesb.2011. 05.043
3 Nazari A, Milani A A. RETRACTED ARTICLE: Modeling ductile to brittle transition temperature of functionally graded steels by fuzzy logic. Compos Part B-Eng, 2011, 46: 6007-6017, https://doi.org/ 10.1007/s10853-011-5563-z

4 Marouf B T, Bagheri R, Mahmudi R. Role of interfacial fracture energy and laminate architecture on impact performance of aluminum laminates. Compos Part A-Appl Sci Manufacturing, 2008, 39: 16851693, https://doi.org/10.1016/j.compositesa.2008.07.010 